\title{
PAWANG DALAM SENI PERTUNJUKAN JARANAN DI DESA SRANTEN BOYOLALI
}

\author{
Hesti Wijayanti \\ Agus Cahyono
Alumni Mahasiswa Jurusan Sendratasik, Fakultas Bahasa dan Seni, Universitas Negeri Semarang
Email: hesti33@yahoo.com

\begin{abstract}
Sari
Seni pertunjukan jaranan di Desa Sranten identik dengan terjadinya kesurupan, karena terdapat pawang yang mengatur jalannya seni pertunjukan jaranan. Latar belakang dalam Penelitian ini peneliti memilih pawang sebagai objek dari penelitian, dikarenakan masih terdapat keinginan untuk mendalami hal-hal yang bersifat spiritual dan masih banyak yang belum tahu proses menjadi pawang. Penelitian ini diharapkan bermanfaat sebagai referensi dan memperluas pengetahuan bagi calon pawang. Penelitian ini menggunakan metode penelitian kualitatif dan pendekatan etnokoreologi. Teknik pengumpulan data yang digunakan adalah teknik observasi, teknik wawancara dan teknik dokumentasi. Teknik analisis data yang digunakan reduksi data, penyajian data dan penarikan kesimpulan. Teknik keabsahan data yang digunakan triangulasi sumber. hasil penelitian yaitu aspek-aspek yang ada dalam seni pertunjukan jaranan: sebelum pertunjukan (ritual, mantra, persiapan penari, properti dan pelaku), saat pertunjukan (gerak, iringan, tata rias dan busana, atraksi, ritual dan mantra, peran pawang) dan sesudah pertunjukan (ritual dan mantra). Peranan pawang yaitu menyadarkan penari yang kesurupan dan mengatur jalannya pertunjukan. Lelaku pawang dari trah keturunan harus berani menjalankan dasar-dasar yang berhubungan dengan gaib. Proses menjadi pawang dapat dilakukan dengan berkunjung kerumah pawang atau guru. Proses menjadi pawang juga harus menaati semua peraturan dan persyaratan yang diberikan pawang kepada calon pawang. Pawang harus mengerti bahasa sandi yang digunakan penari saat kesurupan.
\end{abstract}

Kata Kunci : pawang, seni pertunjukan jaranan, aspek-aspek pertunjukan;

\section{PENDAHULUAN}

Seni pertunjukan jaranan di Desa Sranten sebelumnya terdapat dua kelompok seni pertunjukan yang ada, yaitu kelompok seni pertunjukan Kudo Taruno yang ada di Dukuh Karangbendo dan kelompok seni pertunjukan yang ada di Dukuh Kaworan. Seni pertunjukan di Dukuh Kaworan hanya bertahan 6 tahun. Seni pertunjukan jaranan Kudo Taruna walaupun awalnya hanya tingkat Dukuh sekarang sudah tingkat Desa. Seni pertunjukan Jaranan Kudo Taruno lebih dikenal pada masyarakat di dalam Desa maupun di luar Desa dengan sebutan seni pertunjukan jaranan Desa Sranten.
Seni pertunjukan jaranan di Desa Sranten identik dengan terjadi kesurupan dan atraksi-atraksi yang dilakukan oleh penaripenari jaranan, membuat seni pertunjukan jaranan memiliki daya tarik tersendiri. Sebelum para penari jaranan kesurupan terdapat proses pemanggilan roh halus yang dilakukan oleh pawang. Pawang biasanya menyiapkan sesaji yang digunakan untuk ritual.

Ritus sering mengandung makna upacara, yaitu tindakan atau perbuatan yang terkait oleh aturan-aturan tertentu menurut adat dan agama. Tindakan agama lazimnya dilakukan dalam upacara atau ritus, sehingga dapat pula dikatakan bahwa ritus adalah tindakan (Lubis 2007: 190). 
Kehadiran suatu upacara di dalam suatu masyarakat merupakan ungkapan tertentu yang berhubungan dengan bermacam-macam peristiwa yang dipandang penting bagi masyarakat itu. Penempatan kepentingan di dalam suatu kelompok masyarakat tidak selalu sama bagi kelompok masyarakat lain. Peristiwa-peristiwa yang dianggap penting dilaksanakan sebagai suatu upacara dengan rangkain dan tatanannya. Bentuk ungkapan yang diketengahkan untuk menyambut atau sehubungan dengan peristiwa penting ini juga bermacam-macam sesuai dengan kepercayaan dan tradisi yang sudah dijalani secara turun temurun (Kusmayati dalam Cahyono 2006: 24)

Hubungan atau komunikasi itu bukan sesuatu yang sifatnya biasa atau umum, tetapi sesuatu yang bersifat khusus atau istimewa, sehingga manusia membuat suatu cara yang pantas guna melaksanakan perjumpaan itu, maka muncullah beberapa bentuk ritual. Ritual itu dipandang dari bentuknya secara lahiriah merupakan hiasan atau semacam alat saja. Pada intinya yang lebih hakiki adalah emosi kepercayaan atau sistem keyakinan yang ada. Oleh karena itu upacara ritual biasanya diselenggarakan pada tempat dan waktu yang khusus dan berbagai sarana atau peralatan yang khusus pula (Hadi 2007: 98-99).

Pada seni pertunjukan jaranan di Desa Sranten upacara ritual dilakukan pawang. Pawang di dalam seni pertunjukan jaranan memiliki fungsi untuk membantu kelancaran pada saat seni pertunjukan jaranan berlangsung. Terdapat syarat-syarat khusus yang harus dipenuhi untuk bisa menjadi seorang pawang. Pawang dalam seni pertunjukan jaranan merupakan pawang yang sudah terpilih, terlatih dan sudah dipercayai untuk mengatur jalannya seni pertunjukan jaranan. Pawang dalam seni pertunjukan jaranan dapat menjadi sumber inspirasi bagi orang-orang yang ingin tahu dibalik diri pawang seperti apa perjalanan sebelum menjadi pawang.

Pawang merupakan seseorang yang mempunyai keahlian istimewa yang berkaitan dengan ilmu gaib. Ilmu gaib disebut science occulte. Orang jawa menyebut istilah ini menjadi ngelmu gaib. Di dalamnya terdapat pemahaman terdapat hal-hal yang sulit diterka, sulit terpahami, ramal-meramal dan sebagainya (Rasjidi dalam Endraswara 2011: 67).

Pawang adalah pemimpin grup kesenian kuda kepang atau jaranan yang memimpin jalannya pentas, mengatur persiapan dan perlengkapan pentas. Pawang juga mengatur datangnya indang ke arena pentas dan melepaskan indang dari pemain. Pawang mempunyai keahlian tertentu, yaitu dapat berhubungan dengan alam lain tempat bersembunyinya indang. Pawang adalah pemimpin yang dipilih karena mempunyai keahlian dalam memimpin kelompok, memanggil dan melepas indang, pandai membagi dan mengatur tugas dalam pentas kuda kepang (Wasino 2006: 25-26).

Fungsi pertunjukan yang multi religi dalam kehidupan manusia secara garis besar dapat di kelompokkan menjadi dua, fungsi primer dan fungsi sekunder. Fungsi primer dari seni pertunjukan adalah apabila seni pertunjukan tersebut bertujuan bukan sekedar untuk dinikmati, tetapi untuk kepentingan lain. Fungsi primer meliputi: (1) sebagai sarana ritual, yang penukmatnya adalah kekuatankekuatan yang kasat mata. Para pemain dan peserta di dalam pertunjukannya terlibat bersama-sama sebagai peserta, sehingga seni pertunjukan jeni ini disebut art of participation, (2) sebagai sarana hiburan, yang penikmatnya adalah pribadi-pribadi yang melibatkan diri dalam pertunjukan disebut art of participatiaon, (3) sebagai presentasi estetis, yang pertunjukannya harus dipresentasikan atau disajikan kepada penonton yang disebut art of presentation (Soedarsono dalam Cahyono 2002: 46).

Menurut Wasino (2006: 3) kesenian jaran kepang (kuda lumping, jaran dor, jahilan) merupakan seni pertunjukan tradisional yang keberadaanya sudah ada sejak lama dan sampai sekarang perkembangannya mengalami pasang surut. Hal ini terlihat dari munculnya namanama kesenian tersebut ditiap-tiap daerah mempunyai nama dan ciri khas sendiri-sendiri walaupun kesenian-kesenian pada intinya menggunakan kuda dari kepang sebagai permainan intinya.

Jenis tari jhatilan atau kuda kepang dengan melihat latar belakang sejarahnya merupakan tari rakyat yang paling tua di Jawa. 
Tari yang selalu dilengkapi dengan perlengkapan tari yang terbuat dari anyaman bambu berupa kuda kepang ini lazim dipertunjukkan sampai puncak yaitu saat salah seorang penarinya tidak sadarkan diri (Soedarsono 1992: 95).

Seni pertunjukan dapat dilihat dari tiga fase. Pertama, seni pertunjukan diamati melalui bentuk yang disajikan. Kedua, seni pertunjukan dipandang dari segi makna yang tersimpan di dalam aspek-aspek penunjang wujud penyajiannya. Ketiga, seni pertunjukan dilihat dari segi fungsi yang dibawakannya bagi komponen-komponen yang terlibat di dalamnya. Bentuk, makna dan fungsi saling berhubungan serta merupakan rangkaian yang memperkuat kehendak atau harapan para pendukungnya. Seni pertunjukan dapat dilihat dan didengar melalui bentuk fisik yang disajikan (Kusmayati dalam Cahyono 2006: 69).

Berdasarkan pernyataan yang sudah disampaikan, mengapa peneliti memilih pawang sebagai obyek dari peniliti, dikarenakan lingkungan khususnya di Desa Sranten tidak jauh dari hal-hal mistis dan masih terdapat keinginan untuk mendalami lagi hal yang bersifat spiritual. Peneliti berharap dengan diadakannya penelitian tentang pawang dalam seni pertunjukan jaranan di Desa Sranten Kecamatan Karanggede Kabupaten Boyolali ini dapat bermanfaat bagi semua pembaca agar mengetahui pawang yang sebenarnya. Bermanfaat sebagai referensi dan memperluas pengetahuan bagi calon pawang dan dapat memberikan informasi tentang keberadaan seni pertunjukan jaranan di Desa Sranten agar dapat mengenal dan melestarikan seni pertunjukan jaranan.

\section{METODE PENELITIAN}

Penelitian pawang pada seni pertunjukan jaranan merupakan penelitian dengan menggunakan metode kualitatif dengan sifat deskriptif. Pendekatan yang digunakan pada penelitian ini menggunakan Pendekatan etnokoreologi. Data yang diambil dalam penelitian ini berlokasi di Dukuh Karangbendo Desa Sranten Kecamatan Karanggede Kabupaten Boyolali. Data dan informasi yang diperlukan ditentukan berdasarkan sumber data dan informasi yang terdiri dari narasumber yang dipandang memiliki pengetahuan, wawasan dan informasi dari masalah yang dikaji. Narasumber tersebut yaitu pawang, pemusik dan penari.

Teknik pengumpulan data yang digunakan meliputi observasi, wawancara, dan dokumentasi. Peneliti melakukan observasi pada tanggal 26 Agustus 2015 dan bertempat di lapangan bola voli di Dukuh Karangbendo. Setelah peneliti melakukan observasi terhadap objek yang difokuskan peneliti terhadap diri pawang, peneliti melakukan pengamatan secara langsung dalam seni pertunjukan jaranan. Dimana di dalam seni pertunjukan jaranan pawang menjadi peranan penting dalam pementasan berlangsung. Hasil observasi yang dilakukan peneliti berupa foto, video dan datadata yang berhubungan dengan pawang dan seni pertunjukan jaranan. Hasil penelitian yang dilakukan oleh peneliti mendapat gambaran tentang pawang dalam seni pertunjukan jaranan di Desa Sranten Kecamatan Karanggede Kabupaten Boyolali.

Dalam penelitian ini peneliti menggunakan teknik wawancara sebagai alat bantu dalam pengumpulan data, agar data yang diperoleh jelas, terperinci dan valid. Adapun narasumber yang peneliti wawancarai sebagai berikut: (1) Bapak Nuranto selaku ketua dan pawang dalam seni pertunjukan jaranan memperoleh awal berdirinya seni pertunjukan jaranan dan informasi yang bersangkutan dengan pawang, (2) Bapak Murdiyanto selaku pawang memperoleh informasi yang bersangkutan dengan pawang dan proses sebelum pertunjukan, saat pertunjukan dan sesudah pertunjukan, (3) Bapak Dharmo selaku pawang memperoleh informasi tentang proses menjadi pawang, (4) Mas Ibnu selaku pelatih, penari dan pemusik memperoleh informasi tentang bentuk penyajian seni pertunjukan jaranan, notasi iringan dan persiapan-persiapan yang harus dilakukan sebelum seni pertunjukan dimulai, (5) Bambang selaku penari dalam seni pertunjukan jaranan memperoleh informasi tentang tata busana dan tata rias.

Pemeriksaan keabsahan data dalam penelitian ini menggunakan teknik triangulasi. Teknik triangulasi yang digunakan dalam 
penelitian ini adalah triangulasi sumber untuk menguji kredibilitas data dilakukan dengan cara mengecek data yang telah diperoleh melalui beberapa sumber.

\section{HASIL PENELITIAN DAN PEMBAHASAN}

Seni pertunjukan jaranan di Desa Sranten terbentuk pada bulan September, atas permintaan dari remaja Karangtaruna. Seni pertunjukan jaranan di Desa Sranten awalnya tingkat Dukuh sekarang menjadi tingkat Desa. Seni pertunjukan Kudo Taruno lebih dikenal pada masyarakat luas dengan sebutan Seni pertunjukan jaranan Desa Sranten. Pada seni pertunjukan di Desa Sranten dari dahulu hingga sekarang masih mempertahankan seni pertunjukan dimana di dalam seni pertunjukan terdapat pawang sehingga terjadi kesurupan. Pawang dalam seni pertunjukan jaranan memiliki peranan yang penting.

\section{Aspek-Aspek Dalam Seni Pertunjukan Jaranan}

\section{Sebelum Pertunjukan}

Seni pertunjukan jaranan mempunyai unsur penting untuk kelancaran dalam pertunjukkannya yaitu pelaku. Pelaku yang dimaksud seperti pawang, penari jaranan, pengrawit, sindhen dan penonton. Menjadi penari jaranan tidak ada syarat-syarat khusus yang harus dilakukan. Pengrawit harus menguasai gendhing atau lagu campursari maupun dangdut.

Sebelum seni pertunjukan jaranan diadakan terlebih dahulu pawang mengadakan ritual membuka pintu gaib poro punden. Perlengkapan untuk membuka pintu gaib sebagai berikut: dupa gunung kawi, kemenyan jawa, minyak misik, bunga setaman, kantil, kenanga, tumpeng beserta sayurannya, daging ayam atau ingkung, telur ayam kampong, beras kuning, beras putih dimasukkan takir, pincuk daun pisang raja, buah-buahan, sirih beserta gambir, rokok kertas atau mbako, rokok buatan pabrik, gudang garam merah 2 batang, lilin warna merah dan lampu minyak. Sebelum melakukan serangkain persiapan untuk membuka pintu gaib terlebih dahulu pawang melakukan mandi besar dan menjalankan sholat. Setiap pawang harus mengetahui danyang atau penunggu di Desa. Sebelum melakukan pertunjukan pawang terlebih dahulu melakukan ritual meminta izin pada malam hari untuk keselamatan para penari jaranan.

Sebelum pertunjukan penari melakukan persiapan dengan berlatih mulai hari selasa pukul 15.00 sampai dengan selesai. Properti yang digunakan untuk pertunjukan berupa kuda lumping dan topeng.

\section{Saat Pertunjukan}

Sebelum pertunjukan berlangsung keesokan harinya menyiapkan uborampe untuk menghadirkan makhluk halus datang ke lokasi pertunjukan. Selain itu pawang juga membuat pagar gaib yang bertujuan untuk menghindari hal-hal yang tidak diinginkan dari pihak-pihak yang tidak bertanggung jawab. Adapun sesaji pager gaib yaitu garam, beras kuning, kemenyan, dupa, daun awar-awar, daun opoopo, dadap serep, jarak, alang-alang, tebu ireng, janur kuning, kembang setaman, uang recehan, tumpeng dan jajan pasar. Sesaji diletakkan di setiap sudut lokasi pertunjukan dan di dekat alat peraga atraksi.

Ragam gerak yang digunakan pada seni pertunjukan jaranan di Desa Sranten merupakan ragam gerak yang dibuat sendiri oleh para penari jaranan. Ragam gerak pada seni pertunjukan jaranan di Desa Sranten dibagi menjadi empat babak yaitu: ragam gerak pada babak pertama, ragam gerak pada babak kedua, ragam gerak pada babak ketiga dan ragam gerak pada babak keempat. Pada babak pertama ditarikan oleh 10 penari yaitu: Tika, Anis, Fajar, Lulu, Maya, Sari, Tias, Putri, Nina dan Puput. Ragam gerak pada babak pertama sebagai berikut berjalan, ukel tangan kanan, berjalan, ukel tangan kiri, berjalan, menendangkan kaki, berjalan, angkat kuda, jengkeng, tolehan, membolak-balikkan tangan, tolehan, sembahan, tolehan membolak-balikkan tangan, tolehan, ayunkan tangan kanan, membolak-balikkan tangan, ayunkan tangan kanan, sembahan, ayunkan tangan kanan, membolak-balikkan tangan, ayunkan tangan kanan, membolak-balikkan tangan, ayunkan tangan, sembahan, ayunkan tangan kanan, 
membolak-balikkan tangan, ayunkan tangan, sembahan ayunkan tangan, membolak-balikkan tangan, ayunkan tangan kanan, sembahan, ayunkan tangan kanan, membolak-balikkan tangan, ayunkan tangan, membolak-balikkan tangan, ayunkan tangan, menendangkan kaki, jengkeng, jingkrak dan berjalan. Pada babak pertama tidak menampilkan penari yang kesurupan, karena pada babak pertama hanya sebagai pembuka.

Penari yang menari pada babak kedua terdapat 13 penari yaitu: Danang, Riki, Reka, Candra, Tio, Moko, Yanto, Ibnu, Teguh, Dimas, Bagas, Anang dan Depi. Penari memasuki arena pertunjukan dengan di tandai asalah satu pawang menghentakkan cambuk ke tanah. Setelah itu penari memasuki arena pertunjukan dengan ragam geraknsebagai berikut: jingkrak, menendangkan kaki, berjalan, jingkrak, menendangkan kaki, berjalan, jingkrak, menendangkan kaki, jengkeng, ayunkan kaki, jingkrak, menendangkan kaki, mencak, menendangkan kaki, angkat kuda, menendangkan kaki, tolehan, sembah, tolehan, membolak-balikkan tangan, tolehan, ayunkan tangan kanan, dolanan tangan, ayunkan tangan kanan, dolanan tangan, ayunkan tangan, membolak-balikkan tangan, dolanan tangan, ayunkan tangan, menyamping kanan kiri, ayunkan tangan, jingkrak, menendangkan kaki, melangkah kedepan, menendangkan kaki, jingkrak, menendangkan kaki, jengkeng, ayunkan kaki, dan jingkrak. Setelah selesai menarikan penari kemudian mulai kesurupan. Pada saat kesurupan posisi tangan penari sedang memegang kuda lumping dengan membentuk pola lantai melingkar. Ketika tangan pawang dinaikkan ke atas seketika penari mulai kesurupan. Penari yang kesurupan melakukan gerakan tanpa konsep gerakan yang pasti.

Pada babak ketiga terdapat 5 penari yang menari yaitu: Dika, Riyan, Budi, Adi dan Jaiz. Pada babak ketiga penari masuk ke arena pertunjukan dengan ditandai salah satu pawang memegang cambuk dan dihentakkan ketanah. Penari memasuki arena pertunjukan dengan seorang pawang yang menari bersama-sama. Penari dan pawang memasuki arena pertunjukan dengan gerakan berjalan dengan tidak beraturan. Setelah semua penari memasuki arena pertunjukan, tidak lama satu persatu penari mulai kemasukan mahkluk halus. Terdapat juga penari yang memasuki arena pertunjukan sudah dengan keadaan kesurupan atau kemasukan mahkluk halus. Gerakan yang digunakan oleh penari pada babak ketiga tidak beraturan dan tidak ada konsepnya, dikarenakan penari sedang kemasukan makhluk halus. penari yang kesurupan melakukan gerakan merangkak seperti hewan, ad juga yang berdiri sambil berjalan dengan mata melihat sekeliling penononton.

Penari yang menari pada babak keempat terdapat 10 penari diantaranya: Bambang, Ibnu, Bagus, Aji, Ronal, Janu, Adi, Bayu, Gilang dan Ilham. Ragam gerak pada babak keempat sebagai berikut: mencak, doyong kesamping, dolanan kuda, mencak, berputar, menendangkan kaki, jingkrak, berjalan, jingkrak, berputar, menendangkan kaki, angkat kuda, jengkeng, tolehan, sembahan, tolehan, membolak-balikkan tangan, tolehan ayunkan tangan kanan, membolakbalikkan tangan, menendangkan kaki, membolak-balikkan tangan, dolanan tangan, ayunkan tangan, hentakkan tangan, ayunkan tangan, berputar, ayunkan tangan, hentakkan tangan, ayunkan tangan, berputar, hentakkan kedua tangan, pose (atraksi), berjalan, jengkeng, dolanan kuda, menendangkan kaki, berjalanan, menendangkan kaki, jingkrak dan jengkeng. Proses terjadinya kesurupan pada saat tarian sudah selesai ditarikan oleh penari jaranan. Penari jaranan berkumpul dan membentuk pola lantai lingkaran dengan posisi jengkeng dan kepala mengarah ke bawah. Ketika tangan pawang dinaikkan ke atas seketika penari mulai kesurupan. Penari yang kesurupan melakukan gerakan tanpa konsep gerakan yang pasti. Pada babak keempat menjadi puncak dan sekaligus penutup pada seni pertunjukan jaranan di Desa Sranten.

Iringan yang ada pada seni pertunjukan jaranan berfungsi untuk mengiringi tarian agar dapat menarik perhatian penonton dan mendukung gerak tari yang dilakukan oleh para penari jaranan. Alat musik yang digunakan pada saat pertunjukan yaitu: kethuk, kenong, kempul, gong, gendang ketipung, gendang jawa, bendhe, saron, organ dan drum. Penari jaranan di Desa Sranten membawakan tarian 
dengan penuh semangat sehingga terkesan lincah dan gembira. Tempo yang digunakan cepat sehingga membuat seni pertunjukan jaranan di Desa Sranten lebih meriah dan tidak membosankan.

Sebelum pertunjukan Bpak Nuranto ketua Kudo Taruno, selalu mempersiapkan tempat khusus untuk pawang dan penari. Bapak Nuranto mempersiapkan tempat khusus untuk penari dan pawang agar dapat digunakan untuk mempersiapkan diri sebelum pertunjukan. Alatalat rias yang digunakan untuk merias wajah penari jaranan sebagai berikut: pembersih, penyegar, pelembab, alas bedak, bedak tabur, bedak padat, eye shadow, pemerah pipi, pensil alis dan lipstick. Rias yang digunakan pada penari yaitu rias korektif dan rias fantasi. Tata busana yang digunakan dalam pertunjukan yaitu celana hitam, kain atau jarit, stagen, sampur, celana domprang, ikat kain, ikat kuluk, gelang kaki dan gelang tangan.

Alat peraga atraksi yang digunakan yaitu lampu neon, genteng, kelapa, bara apai, sepeda montor dan papan, ayam hidup, rokok, padi, singkong dan kopi pahit. Biasanya alat peraga diletakkan didekat sesaji pager gaib.

Peran pawang dalam seni pertunjukan jaranan yaitu mengadakan serangkaian ritual pada saat sebelum pertunjukan, saat pertunjukan, sesudah pertunjukan, mengeluarkan makhluk halus dari tubuh penari, untuk mengatur jalannya pertunjukan dan pawang juga yang memimpin seni pertunjukan jaranan. Peran pawang dapat terlihat ketika seni pertunjukan jaranan berlangsung. Pada saat penari kesurupan dimana pawang akan melakukan proses mengeluarkan makhluk halus.

Pada babak kedua, seni pertunjukan jaranan mulai menampilkan penari yang kesurupan. pada tahap pertama para penari membentuk posisi lingkaran dengan memegang kuda lumping. Pada tahap kedua pawang memasuki lingkaran dan penari bersiap-siap melakukan proses terjadinya kesurupan. selanjutnya pawang menaikkan tangan ke atas dan menaburkan bunga, seketika itu penari jaranan mulai kesurupan. Beberapa penari jaranan meminta ayam hidup, ada juga penari yang melakukan atraksi memecahkan dua genting dengan kepala.
Pada babak ketiga tidak membutuhkan waktu yang lama untuk kesurupan. Pada babak ketiga atraksi yang dimunculkan yaitu memecahkan lampu neon dengan kepala, memakan pecahan lampu neon, memakan kayu yang dibakar. Terdapat pula penari jaranan yang tadi sudah menari dibabak kedua, tiba-tiba memasuki arena pertunjukan dan mulai kesurupan. Penari yang kesurupan meminta ikat kepala sebagai syarat agar makhluk halus yang ada di dalam tubuh bisa keluar.

Puncak dari seni pertunjukan berada pada babak keempat sebagai penutup pada seni pertunjukan jaranan yang berlangsung. Proses terjadinya kesurupan pada saat tarian sudah selesai ditarikan oleh penari jaranan. Penari jaranan berkumpul dan membentuk pola lantai lingkaran dengan posisi jengkeng dan kepala mengarah ke bawah. Pawang yang ada di dalam lingkaran dengan cepat menaikkan tangan ke atas dengan posisi badan berdiri tegak dan kepala menghadap ke atas. Pada babak keempat atraksi yang dimunculkan yaitu memecahkan 15 genting dengan kepala, memakan kelapa muda, memakan kayu yang dibakar dan atraksi dimana salah satu penari yang kesurupan tidur di atas kain jarit dan dilewati sepeda montor di atas tubuh penari yang kesurupan.

\section{Sesudah Pertunjukan}

pada saat seni pertunjukan jaranan selesai untuk penari perempuan membasuh muka dengan air bunga. Penari laki-laki karena memiliki ilmu kebatinan, penari laki-laki juga melakukan ritual untuk pembersihan diri dari makhluk halus selain membasuh muka dengan air bunga yang sudah disediakan pawang dilokasi pertunjukan.

Setelah seni pertunjukan selesai tugas pawang selanjutnya mengembalikan makhluk halus kealamnya dengan membacakan mantra penutup pintu gaib. Pawang melakukan ritual terakhir untuk mengembalikan makhluk halus yang memasuki penari dengan cara sebagai berikut: pawang membacakan mantra 10 kali, puasa mutih 7 hari, tidak makan 2 hari, melakukan wirit lailah haillah 90.000 (tidak makan dan minum jika belum selesai), melakukan wudhu jika sholat, tidak boleh 
keluar dari payan (tempat untuk melakukan ritual), dan kirim do'a kepada arwah ahli leluhur tengah malam dilokasi keramat untuk penutup dan keselamatan.

\section{Proses Menjadi Pawang}

Lelaku pawang dari sifat tarah
keturunan menjalankan dasar-dasar yang berhubungan dengan gaib: (1) berani melakukan ritual ditempat yang keramat, (2) berani zaroh ditempat pepunden, (3) menjalankan puasa pati geni, (4) harus memahami dasar tari kuda lumping, (5) bisa menyiapkan makanan berupa sesaji, (6) harus melakukan jenis-jenis tarian adat yang ada dilokasi, (7) bisa memahami berbagai macam jenis bentuk gamelan tradisional.

Ada juga lelaku pawang sebelum menjadikan dirinya seorang pawang yaitu sebagai berikut: (1) harus sowan atau mengadakan ritual dimakam para raja-raja ditanah Jawa, (2) ritual atau Zaroh ditempat wali, (3) harus mandi tengah malam atau berendam sambil menghafalkan ayat-ayat Tuhan, (4) Mengadakan ritual di pelataran keramat atau masjid dengan menggunakan sesaji lemgkap (buah-buahan, makanan adat tradisional, tumpeng, lembaran ayam 7 lembar (7 ingkung+ayam 1 kepal, kembang setaman 2 gelas, kembang kantil, dupa, kemenyan jawa, jajanan pasar), 7 Krowotan (singkong, telas, ubi dan lain-lain), dan pala wija (jagung, padi, kelapa), dan (5) mengadakan kirim arwah ahli leluhur. Pawang sendiri harus mengerti bahasa sandi yang digunakan penari yang kesurupan.

Proses menjadi pawang dapat dilakukan dengan berkunjung langsung kerumah pawang. Biasanya yang akan menjadi pawang yaitu anak laki-laki, karena dianggap lebih mampu dalam proses menjadi pawang dan lebih memiliki kekuatan yang lebih besar dari anak perempuan. Penari jaranan juga dapat menjadi pawang, karena sudah memiliki ilmu kebatinan dan sudah mengerti tentang pawang. Hasil penelitian dalam melakukan wawancara dengan Bapak Dharmo selaku pawang dalam seni pertunjukan jaranan di Desa Sranten sebagai berikut.
Jika ingin menjadi pawang harus menjalankan persyaratan berupa melakukan beberapa puasa sebagai berikut: (1) puasa ngembang, (2) setelah selesai melakukan bancaan niatan untuk tujuannya apa kemudian tasyakuran dengan wujud nasi tumpeng ayam ingkung, (3) puasa ngireng, (4) bancaan ketan hitam, (5) puasa muteh.

Puasa juga dilakukan pada hari-hari tertentu yang sudah ditentukan oleh pawang atau guru.

Pencapaian dalam melakukan lelaku tidak akan lepas dari ritual, mantra dan sesaji. Pada saat melakukan semedi, pelaku ritual atau pawang juga membawa sesaji berupa kembang tujuh rupa, kemenyan, bunga setaman ditaruh digelas dan diisi air dan dupa. Semedi pada umumnya dilakukan ditempat-tempat keramat agar memperoleh kekuatan. Terkait dengan waktu semedi biasanya dilakukan pada waktu tertentu seperti hari selasa kliwon dan jumat kliwon.

Bapak Dharmo sebelum menjadi pawang terlebih dahulu mendalami ilmu kebatinan kepada gurunya. Mulai mendalami ilmu kebatianan sejak usia 12 tahun disalah satu padepokan yang ada di Boyolali. Pada saat menjalankan ilmu kebatinan untuk mendapatkan tingkatan yang lebih tinggi beliau juga harus menerima tantangan dan juga ujian yang dilakukan oleh gurunya. Perjalanan beliau tidak sekedar mendalami, beliau juga melakukan semedi di gua pada waktu tertentu dan ditempat-tempat yang dianggap sakral.

Pada saat menjalankan semedi harus tetap fokus dengan tujuan dalam melakukan semedi. Beliau juga menjalankan puasa sesuai dengan perintah dari gurunya. Perjalanan beliau selama mendalami ilmu kebatinan sudah mendapatkan benda-benda pusaka dalam berbagai wujud seperti: berbagai jenis batu mustika dan juga keris. Proses menjadi pawang harus dilaksanakan dengan penuh tanggung jawab, agar tercapai apa yang diinginkannya. Sampai saat ini beliau juga masih menjalankan ritual-ritual yang diperintahkan gurunya. Sebelum menjadi pawang beliau juga mendapatkan kepercayaan dari masyarakat bahwa beliau memiliki kekuatan yang lebih dari sekedar manusia biasa. Bapak Dharmo 
mendapatkan kepercayaan masyarakat di Desa Sranten untuk menjadi salah satu pawang. Semenjak beliau mendapatkan kepercayaan untuk menjadi pawang, beliau selalu bertanggung jawab dalam menjalankannya.

\section{Simpulan}

Aspek yang ada pada seni pertunjukan jaranan yaitu pelaku, ritual, ragam gerak, tata rias dan busana, property, iringan dan pawang dakam seni pertunjukan jaranan. Sebelum pertunjukan diadakan ritual membuka pintu gaib. Setiap pawang harus mengerti danyang atau penunggu desa. Pawang juga melakukan ritual meminta izin untuk keselamatan para penari jaranan. Pada saat dilokasi sebelum diadakan pertunjukan pawang memasang pager gaib dan menyiapkan uborampe. Uborampe digunakan untuk menghadirkan makhluk halus dengan menggunakan mantra. Setelah selesai pertunjukan pawang mengembalikan makhluk halus kealam gaib dengan membacakan mantra penutup pintu gaib.

Tata rias yang digunakan yaitu rias korektif dan rias fantasi. Pada rambut penari wanita hanya digerai saja. Tata busana yang digunakan yaitu celana hitam, kain atau jarit, stagen, sampur, celana domprang, ikat kain, ikat kuluk, gelang kaki dan gelang tangan. Alat musik yang digunakan untuk mengiringi yaitu: kethuk, kenong, kempul, gong, gendang ketipung, gendang jawa, bendhe, saron, organ dan drum.

Pawang dalam seni pertunjukan jaranan sangat berperan penting. Proses kesurupan sudah diatur oleh pawang. Jika tidak ada pawang seni pertunjukan jaranan tidak akan berjalan dengan lancar. Pada saat penari kesurupan, tugas pawang dapat terlihat dengan jelas. Pada saat kesurupan pawang berusaha mengendalikan penari yang kesurupan. Pada saat kesurupan penari juga melakukan atraksiatraksi berupa memecahkan genteng, memakan ayam hidup dan sebagainya.

Proses menjadi pawang bisa dilakukan dengan cara memperdalam dan mempelajari ilmu yang sudah ada dalam diri seseorang. Cara melaksanakannya bisa datang langsung kerumah guru atau pawang. Proses menjadi pawang juga bisa dilaksanakan dari keturunan yang diturunkan turun temurun. Pencapaian dalam melaksanakan lelaku pawang tergantung dari niatan yang dilakukan oleh masing-masing individu.

Bahasa sandi juga perlu diketahui oleh para pawang. Bahasa sandi digunakan oleh pawang untuk mengetahui apa yang diinginkan penari yang kesurupan. Karena penari yang kesurupan tidak dapat berbicara, hanya menggunakan bahasa sandi melalui gerakan tangan atau badan.

\section{Saran}

Berdasarkan hasil penelitian dapat diambil saran-saran sebagai berikut. Bagi pawang dan penari lebih meningkatkan latihan agar pada saat pertunjukan lebih maksimal lagi. Bagi pelatih sekaligus penari agar dapat memfariasikan gerakan supaya tidak terlihat monoton. Seni pertunjukan Kudo Taruno di Desa Sranten harus terus dipertahankan dan dijaga pelestariannya. Perlu adanya langkah dalam melibatkan genari muda untuk menjadi seoarang pawang, supaya generasi muda juga dapat melestarikan seni pertunjukan jaranan yang didalamnya melibatkan seorang pawang.

\section{DAFTAR PUSTAKA}

Cahyono, Agus. 2002. Eksistensi Tayub Dalam Sistem Transmisinya. Yogyakarta: Yayasan Lentera Budaya.

Cahyono, Agus. 2006. Seni Pertunjukan ArakArakan Dalam Upacara Tradisional Dugdheran di Kota Semarang. Harmonia Jurnal Pengetahuan dan Pemikiran Seni, VII (03), 67-77. Semarang: UNNES PRESS.

Cahyono, Agus. 2006. Pola Pewarisan NilaiNilai Kesenian Tayub. Harmonia Jurnal Pengetahuan dan Pemikiran Seni, VII (01), 23-36. Semarang; UNNES PRESS.

Ambarwangi, S., \& Suharto, S. (2014). REOG AS MEANS OF STUDENTS' APPRECIATION AND CREATION IN ARTS AND CULTURE BASED ON 
THE LOCAL WISDOM. Harmonia: Journal Of Arts Research And Education, 14(1), 37-45. doi:http://dx.doi.org/10.15294/harmonia. v14i1.2789

Wiyoso, J. (2012). KOLABORASI ANTARA JARAN KEPANG DENGAN CAMPURSARI: SUATU BENTUK PERUBAHAN KESENIAN TRADISIONAL. Harmonia: Journal Of Arts Research And Education, 11(1). doi:http://dx.doi.org/10.15294/harmonia. v11i1.1497

Irianto, A. (2016). The Development of Jathilan Performance as an Adaptive Strategy Used by Javanese Farmers. Harmonia: Journal Of Arts Research And Education, $\quad 16(1), \quad 38-48$. doi:http://dx.doi.org/10.15294/harmonia. v16i1.5213

Astini, S., \& Utina, U. (2011). TARI PENDET SEBAGAI TARI BALIH-BALIHAN ( Kajian Koreografi) (Pendet Dance as Welcome Dance Coreography Research). Harmonia: Journal Of Arts Research And Education, 8(2). doi:http://dx.doi.org/10.15294/harmonia. v8i2.789

Endraswara, Suwardi. 2011. Agama Jawa Dalam Menyusuri Jejak Spriritualitas Jawa. Yogyakarta: Lembu Jawa.

Hadi, Sumandiyo.Y. 2007. Kajian Tari "Teks dan Konteks". Yogyakarta: Pustaka Book Publisher.

Kusudiarjo, Bagong. 2000. Dari Klasik Hingga Kontemporer. Yogyakarta: Padepokan PRESS.

Lubis, Safrinal dkk. 2007. Jagad Indonesia dalam Dialegtika yang Sacral dan yang Profane. Yogyakarta: Ekspresibuku.

Soedarsono. 1992. Pengantar Apresiasi Seni. Jakarta: Balai Pustaka.
Wasino. 2006. Jaran Kepang. Semarang: Dinas Pendidikan dan Kebudayaan Museum Jawa Tengah Ronggowarsito. 